\title{
i
}

\section{Don Bosco}

\section{y la formación profesional}

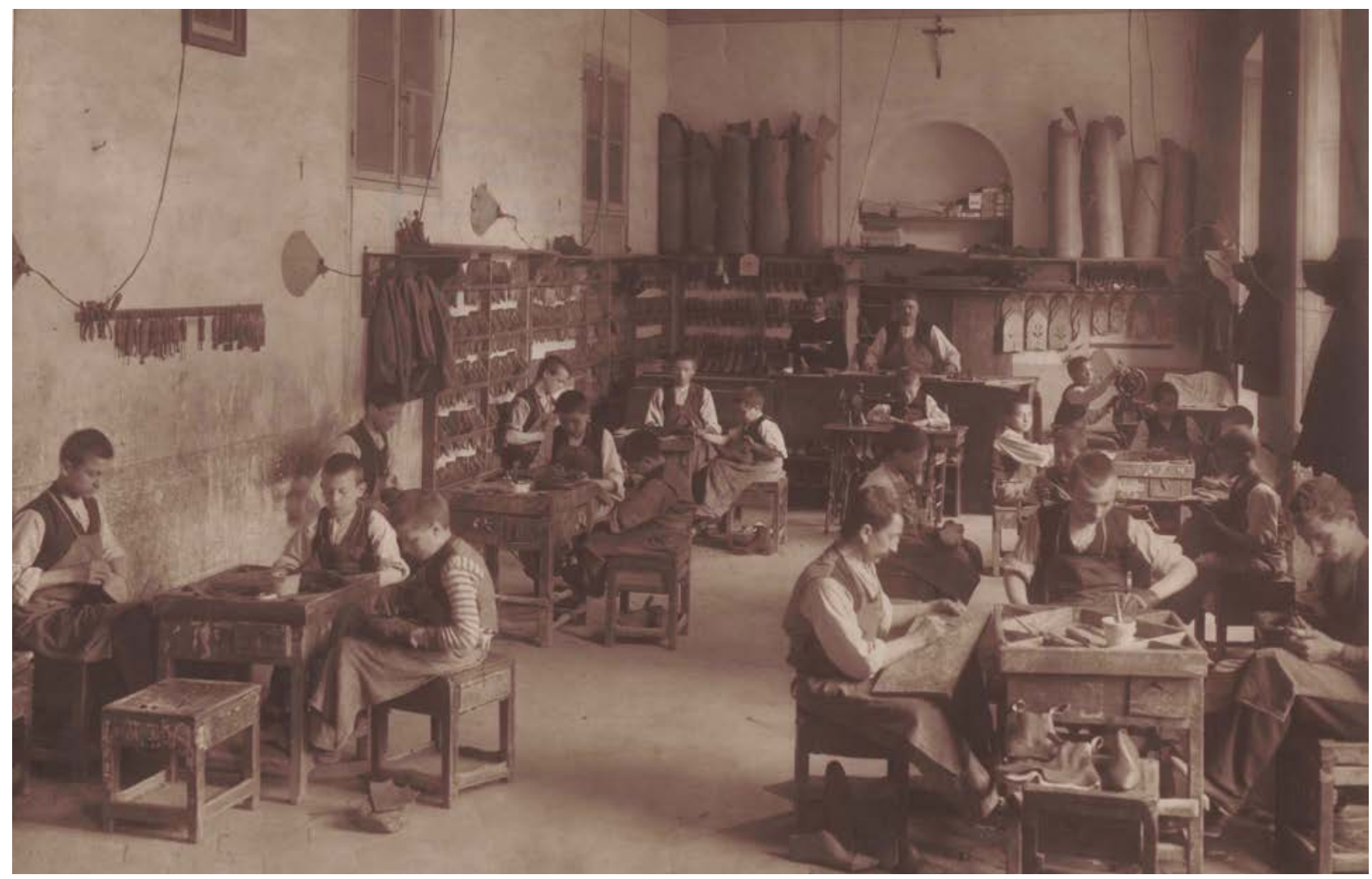

Don Bosco, guiado por un sueño e interpelado por la realidad que vivió en el Turín del siglo XIX, supo dar una respuesta educativa, desde su sistema preventivo, a las necesidades juveniles. La

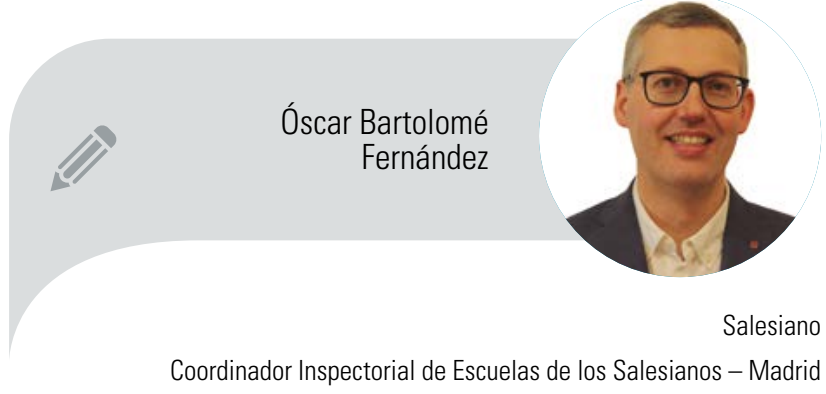
creación de los talleres y su preocupación

por el mundo obrero harán que con el paso del tiempo la formación profesional sea una seña de identidad de los Salesianos y Juan Bosco se convierta en el patrón de la formación profesional en nuestro país. 


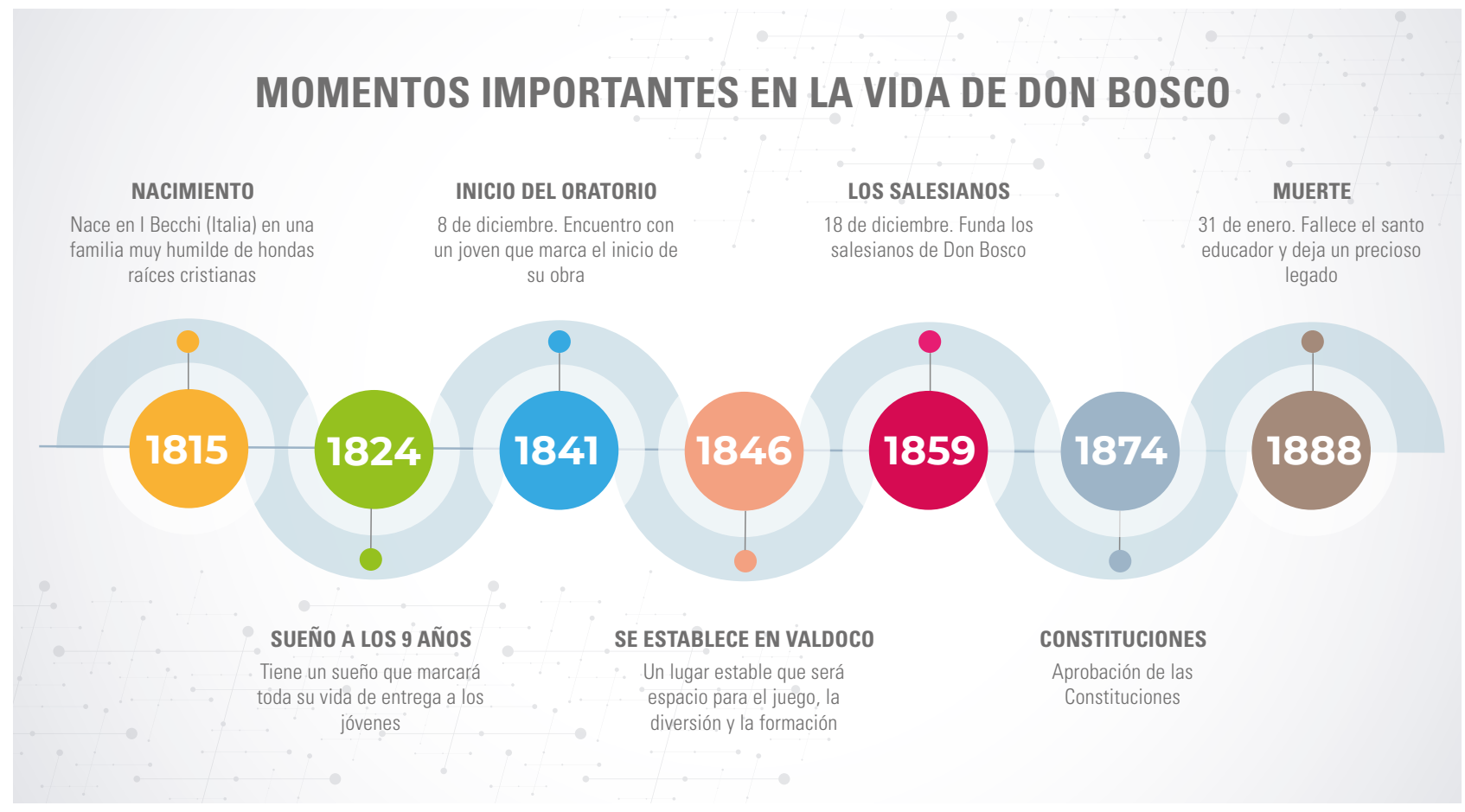

\section{Un sueño que se hará realidad}

Nos encontramos en un pueblecito del norte de Italia. Corre el año 1815, un año marcado por numerosos cambios en Europa. En I Becchi nace Juan Bosco, un niño que crecerá en el seno de una familia en la que no faltarán las dificultades: la escasez, la pérdida del padre cuando Juan no tenía todavía dos años, la presión para trabajar, la solución de abandonar el hogar familiar para evitar problemas con su hermanastro y compaginar el trabajo en el campo o en diferentes oficios manuales, como el ser aprendiz de sastre, con el estudio.

Aunque lo comprenderá con el paso del tiempo, a los 9 años un sueño marcará su futuro: unos chicos violentos, que blasfeman, le hacen ponerse en medio de ellos para evitar el pecado. En el sueño ve cómo "feroces animales" se convierten en "mansos corderos". Se le propone también el método: "no con golpes, sino con la mansedumbre y con la caridad deberás ganarte a estos tus amigos". Una labor que desarrollará a lo largo de su vida con los jóvenes.

El 8 de diciembre de 1841, tal como él nos lo cuenta, en la sacristía de la Iglesia de San Francisco de Asís de Turín tiene lugar un acontecimiento que pondrá las bases del Oratorio: el encuentro con un joven Ilamado Bartolomé Garelli y una sencilla catequesis.

\section{Un duro ambiente que interpela}

Pensar en Turín en pleno siglo XIX nos lleva a descubrir personas y situaciones familiares muy complicadas, jóvenes explotados, condiciones laborales precarias, la urgencia de ayudar a los jóvenes a descubrir un proyecto de futuro que dé sentido a sus vidas..

\section{Acompañado por su fiel consejero \\ Don Cafasso tomará una decisión \\ definitiva que él mismo expresa así: \\ "He consagrada mi vida al bien de la \\ juventud"}

En esta ciudad industrial Don Bosco descubre horrorizado numerosos niños y jóvenes que han dejado sus pueblos y aldeas, muchos de ellos son huérfanos, no pocos trabajan en unas condiciones precarias y son explotados, no tienen un lugar decente donde residir, sus derechos, si es que existe alguno, no son respetados... Conoce de primera mano la realidad que existe en las cárceles y en las calles de la ciudad. Acompañado por su fiel consejero Don Cafasso tomará una decisión definitiva que él mismo expresa así: "He consagrado mi vida al bien de la juventud".

Desde finales de 1841 hasta 1846, año en el que se instala el primer oratorio definitivamente en Valdocco, serán muchas las experiencias vividas por Don Bosco que marcarán su pasión por los jóvenes y sus proyectos para dar una casa estable a estos chicos, una buena instrucción y ayudarles a descubrir su camino en la vida, según la religión cristiana. En este periodo el oratorio itinerante, tal como se narra en las Memorias del Oratorio, en general, "se componía de picapedreros, albañiles, estucadores, adoquineros, canteros y otros que venían de pueblos lejanos", 


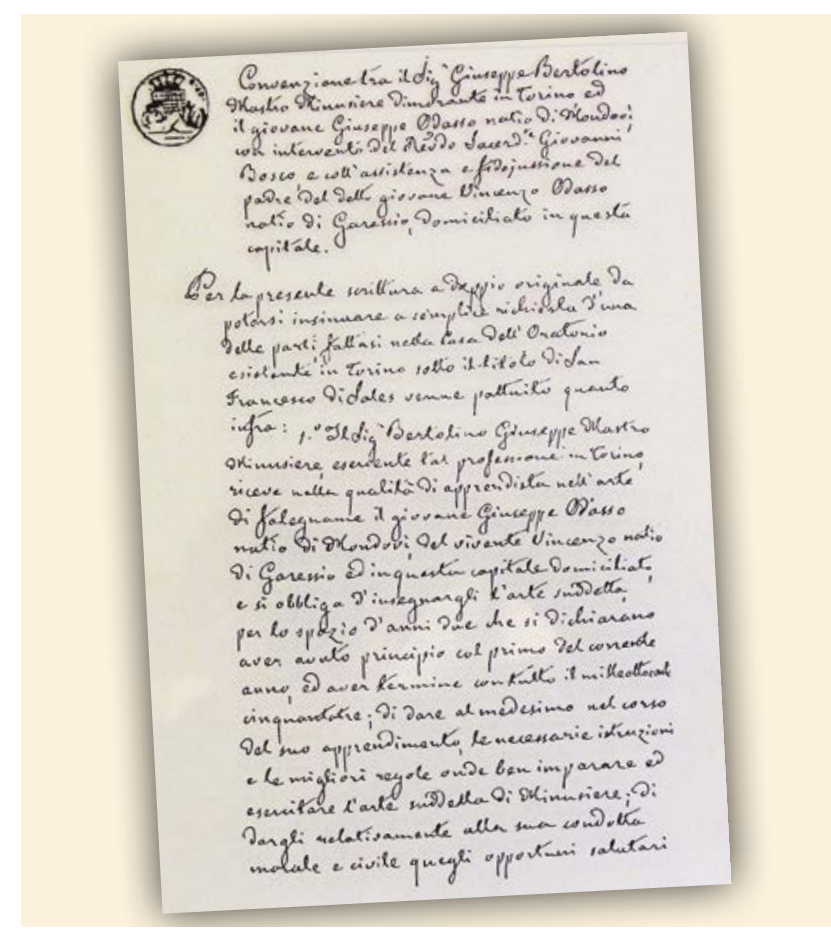

chicos poco cualificados y que "como no conocían dónde se encontraban las iglesias ni conocían a compañeros, estaban expuestos a peligros de perversión, sobre todo en los días de fiesta".

En este periodo Don Bosco dedicaba todo el domingo a estar con los chicos y durante la semana iba a visitarlos a sus puestos de trabajo, como un amigo que se acercaba y preocupaba de ellos. También visita a los delincuentes para hacerles ir al Oratorio al salir de la cárcel y comenzar con ellos un proceso de transformación educativa, de reeducación. En definitiva, entra en contacto directo con la juventud obrera y con los inmigrantes con el objetivo de liberarlos de las graves situaciones que vivían y ofrecerles un futuro mejor.

\section{Un lugar estable donde educar}

Una vez instalado con su madre, Mamá Margarita, en Valdocco continúa dando forma a su proyecto educativo. En 1847 ya están en funcionamiento las clases nocturnas y un sencillo internado, que en mayo acoge al primer interno y rápidamente se multiplicarán los residentes. Su internado pretende ser una casa para los muchachos necesitados que se encuentran solos y abandonados en la vida, sin profesión, sin instrucción y sin nadie que los oriente al trabajo, al orden y a la religión.

Posteriormente comenzarán a convivir en la casa anexa del Oratorio tanto los jóvenes estudiantes como los artesanos, pero tendrán que salir a estudiar a la ciudad. Don Bosco toma la decisión de visitarlos con frecuencia para darse cuenta de las condiciones de trabajo y pedir a sus jefes mejoras en sus condiciones de aprendizaje; se convierte así en padre y tutor de los

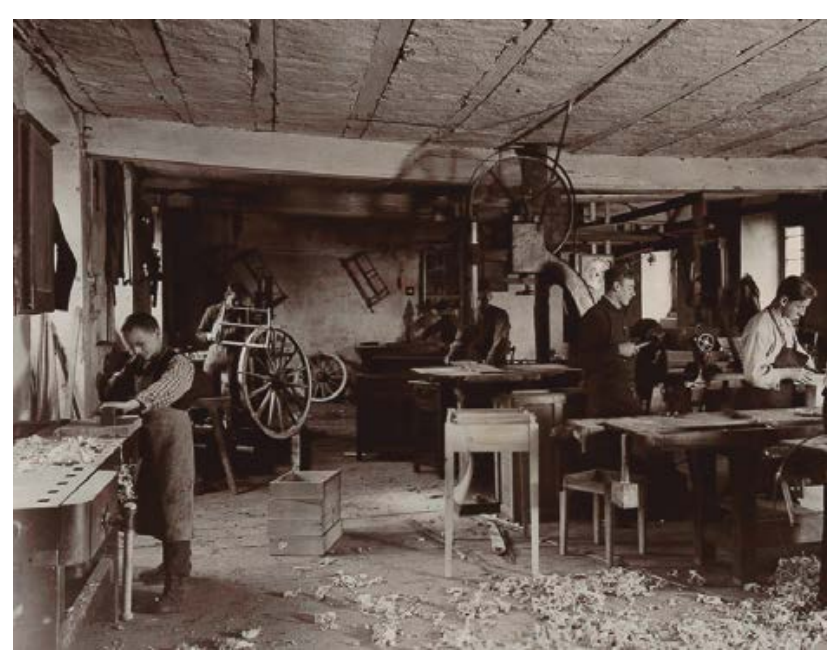

\section{Entra en contacto directo con la juventud obrera y con los inmigrantes con el objetivo de liberarlos de las graves situaciones que vivían y ofrecerles un futuro mejor}

jóvenes que residían en el Oratorio, muchos eran huérfanos o estaban lejos de sus familias. Durante los años 1847-1852 realizó numerosos contratos de trabajo para regular la práctica de las relaciones entre el patrono y el joven, asegurando la gradualidad del aprendizaje del oficio, el descanso dominical, un salario, la cantidad del trabajo, etc. Tenemos un ejemplar original de uno de estos contratos, del 8 de febrero de 1852.

En este periodo, Don Bosco siguió potenciando la cultura como maestro y pedagogo, así llevó a cabo la iniciativa de preparar y publicar libros escolares, tanto religiosos, como la Historia eclesiástica para uso de las escuelas (1845), como civiles, por ejemplo: El sistema métrico decimal reducido a simplicidad (1846). Su pasión educativa, desde el compromiso cristiano, le lleva a acoger a numerosos jóvenes que no tienen una situación favorable para desarrollarse como personas y cristianos. No pretende simplemente ayudar a cómo enseñar un oficio o profesión, intenta dar una cultura básica a quienes, en algunos casos, son analfabetos y evangelizar a estos jóvenes adaptando los métodos de la época y favoreciendo 


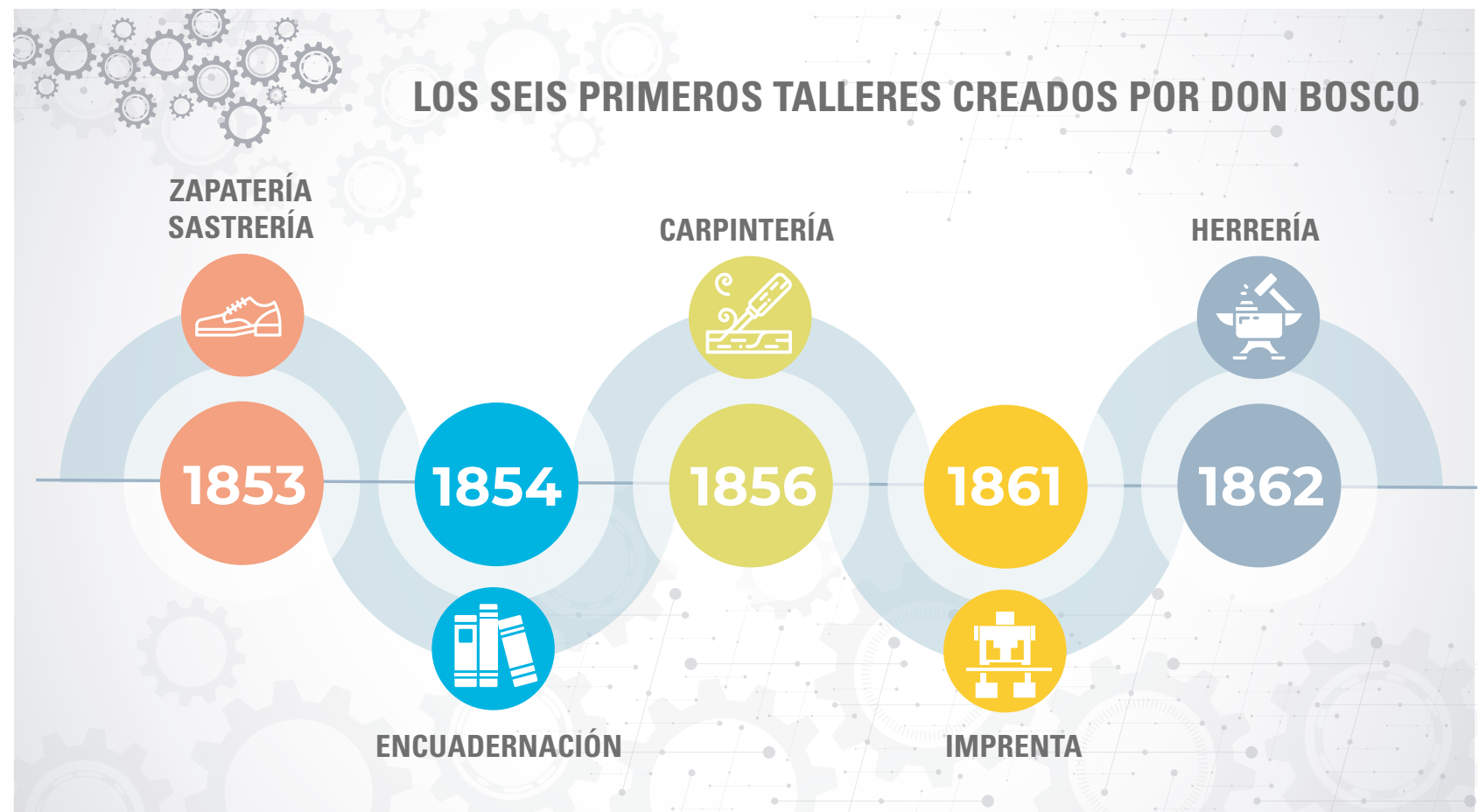

experiencias positivas y agradables para los jóvenes: la música, el juego, los paseos... Confía en la dignidad de estos jóvenes y les ofrece una visión del mundo y de la persona que, desde la fe, busca la promoción de la persona humana. En 1859 completará los cursos de enseñanza secundaria, gimnasio, en los locales del Oratorio, evitando salir a la ciudad.

\section{Los primeros "talleres" en Valdocco}

Oficialmente podemos decir que la fecha que marca el inicio de los primeros "talleres" _laboratori- en Valdocco es el año 1853. Don Bosco instala en una salita un modesto taller de zapatería para jóvenes aprendices. Desde este momento, además de los estudiantes, formarán parte de la casa los "jóvenes artesanos". El mismo Don Bosco nos dice que "en el año 1856 se establecieron de manera permanente las clases y los talleres en la casa del Oratorio, con grandes ventajas para todos". A este taller le siguen el de sastrería en el mismo año, encuadernación (1854), carpintería (1856), imprenta (1861) y herrería (1862). Hasta la muerte de Don Bosco surgirán otros talleres: sombrerería, panadería, fundición...

La idea de la "formación profesional" es un sistema que se encuentra fuera de los modelos estatales de educación, que trata de dar respuesta a necesidades concretas que exigen una actuación urgente en un contexto en el que ya se estaban dando respuestas similares: Ludovico Pavoni había fundado en Brescia en 1821 el Instituto San Bernabé para formar a jóvenes pobres en algún oficio. En los años que precedieron a la apertura del primer taller en el Oratorio diversas publicaciones destacaban la importancia de la formación de estos jóvenes. Pudo leer la revista

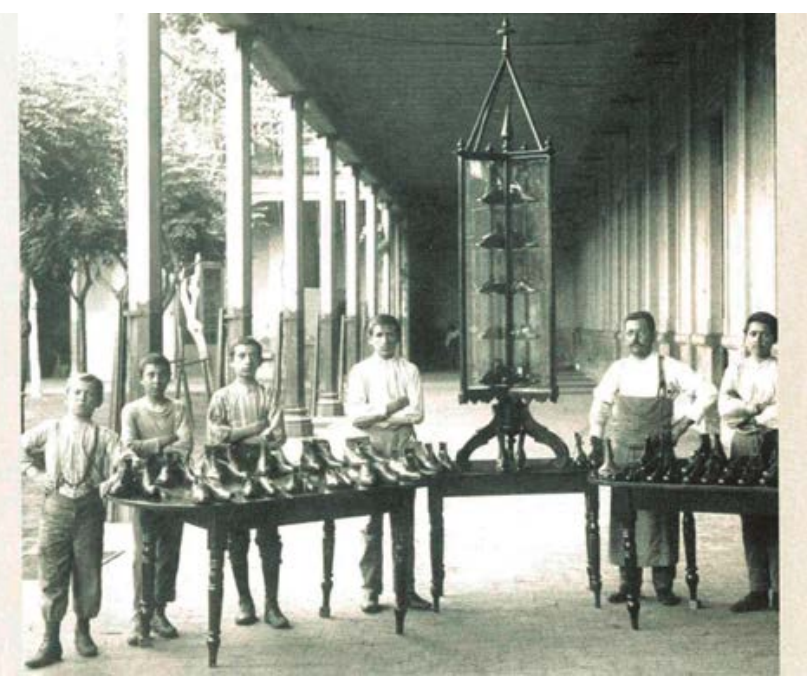

L'Educatore Primario y conocer las experiencias en la misma ciudad de Turín creadas para jóvenes aprendices: el Regio Albergo delle Virtù o el Collegio degli Artegianelli. También había experiencias similares en la vecina Francia.

Por su experiencia personal podía entender las necesidades de los jóvenes con los que se relacionaba y para los que tratará de crear una casa, una familia, de la que ellos carecían. Estos talleres, con sus ensayos y pruebas, se desarrollan en un contexto marcado por las profundas transformaciones económicas, por los cambios en las relaciones entre los obreros y los patronos, las injusticias sociales, el fuerte aumento de la desocupación... y cuentan con una persona que ha decidido entregar a los jóvenes hasta su último aliento. 

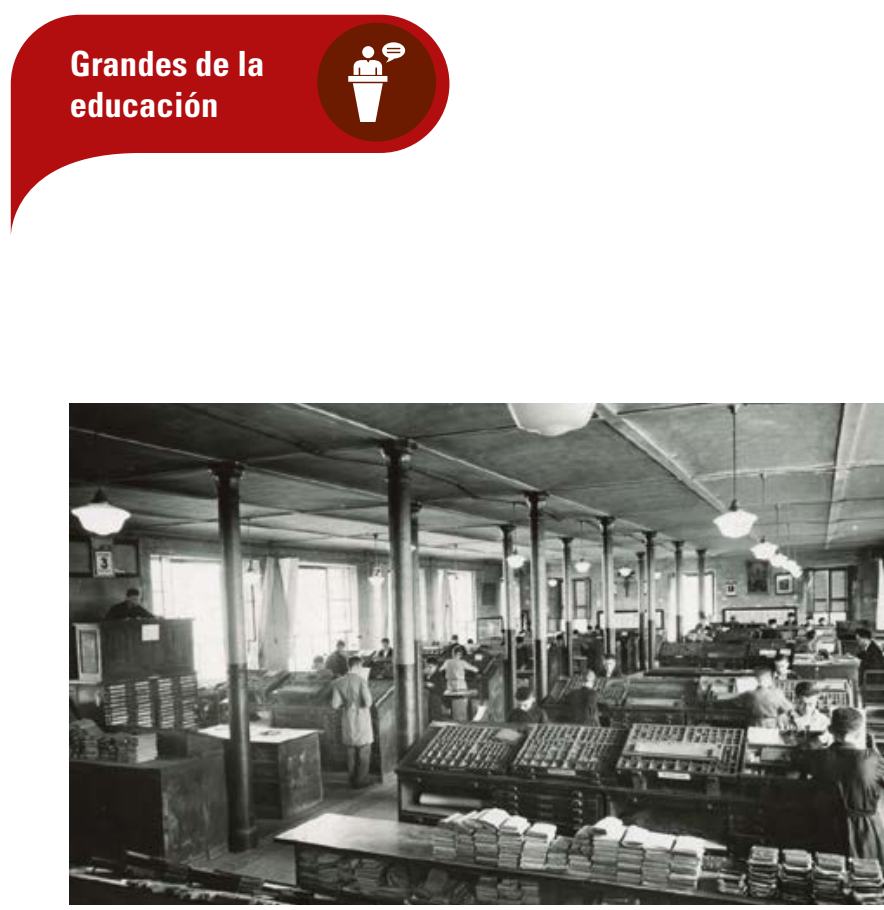

\section{El objelivo es que hayan adquirido un \\ oficio con el que ganarse honradamente \\ el pan de la vida, estén bien instruidos}

en la religión y tengan los conocimientos

científicos oportunos a su estado

\section{La escuela profesional salesiana entre 1856 y 1886}

Al principio los artesanos residían en Valdocco, pero no tenían allí su puesto de trabajo. Después vinieron los talleres, pero los jefes de taller eran externos. Finalmente, el personal pudo ser también interno, los salesianos, y realizar toda la formación en la misma casa. Los primeros talleres surgen por la necesidad de dar respuesta a las necesidades de la residencia-internado: zapatería, sastrería, encuadernación y carpintería. La apertura de la imprenta el año 1861 se debe fundamentalmente a la creciente actividad literaria y publicitaria de Don Bosco con las Lecturas católicas y otras numerosas publicaciones y opúsculos. El taller de herrería sirvió para las constantes ampliaciones de la casa madre de los salesianos. Como indica R. Alberdi, "de esta manera se constituyó el primer centro de Formación Profesional de los salesianos". Un centro que respondía a las necesidades de los jóvenes y también al sueño hecho realidad del propio Don Bosco.

En estos primeros momentos Don Bosco era el director del Oratorio y aparecía también como el propietario y titular de los talleres. Esto le genera algún problema porque desde fuera se le ve como una persona que, con la excusa de educar, tiene una actividad productiva que entra en concurrencia con las empresas de la ciudad. El caso más claro es el de las dificultades que le generó la imprenta instalada en 1861, pero superadas las dificultades iniciales ha permanecido activa con gran prestigio hasta el año 2012. Él se justificaba diciendo que hacía pura beneficencia y que su institución tenía un carácter escolar.

Aunque la Sociedad Salesiana cada vez se dedicó más a los estudiantes, no se olvidó de los jóvenes artesanos y se preocupó por promover las vocaciones de los salesianos coadjutores, que debían surgir de entre los artesanos. La historia del salesiano coadjutor crecerá de la mano de las escuelas profesionales. En su origen puede estar la necesidad de personal propio, maestros de casa cualificados técnica, pedagógica y religiosamente para los talleres.

Don Bosco observa durante 15 años la realidad de esta "escuela de formación profesional", pues hasta el año 1871 no abre otra con este tipo de enseñanza en Sampierdarena. Irá gestando poco a poco lo que será la formación profesional. En las Constituciones aprobadas el año 1874 se recoge como un fin de la Congregación la necesidad de abrir casas para jóvenes a los que se eduque en la fe católica y se les instruya en algún arte y oficio para darles un futuro digno.

\section{Los últimos impulsos dados por Don Bosco a la formación profesional}

En el cuarto capítulo general de los salesianos (1886), el último celebrado en vida de Don Bosco, se aborda el tema de la formación que hay que dar y los medios necesarios para desarrollar la vocación entre los jóvenes artesanos. En las deliberaciones se recoge la que será llamada por D. Ceria la Parva Charta sobre los jóvenes artesanos, una especie de estatuto de las escuelas profesionales salesianas. En la introducción se recoge el objetivo: "el fin, que se propone la Pía Sociedad Salesiana al acoger y educar a estos jóvenes artesanos, es el de educarlos en modo que, al salir de nuestras casas con su experiencia formativa realizada, hayan adquirido un oficio con el que ganarse honradamente el pan de la vida, estén bien instruidos en la religión y tengan los conocimientos científicos oportunos a su estado". Se les ha de dar una adecuada formación religiosamoral, intelectual y profesional. Con respecto a esta última se hace referencia al conocimiento teórico y práctico del oficio, a la orientación profesional, a los ejercicios progresivos que se han de realizar, a un plan quinquenal de formación (quizás nos puede recordar los cinco años de la antigua FP antes de la entrada en vigor de la LOGSE en nuestro país), 


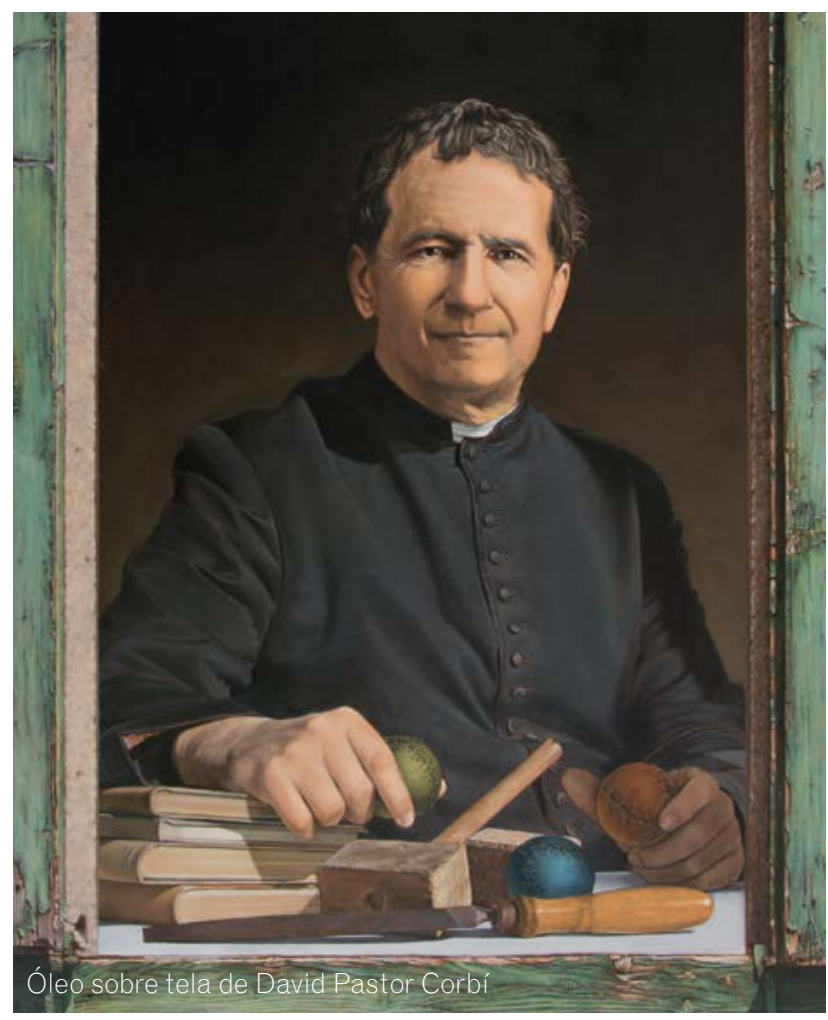

exposiciones periódicas, calificaciones semanales y personal bien preparado y que se responsabilice de esta tarea.

A partir del año 1887 el órgano supremo de gobierno de la Congregación contará con un salesiano cualificado, y cada vez con más competencias, que se responsabilizará de todo lo que se refiere a la formación profesional en la Congregación salesiana.

Don Bosco no fue el primero en organizar talleres de aprendizaje, pero la escuela profesional salesiana tiene sus propias características por la intención, el método y el estilo original. Con el paso de los años, ya en la década de los sesenta del siglo XIX, cada vez se verá más claramente cómo los talleres salesianos fueron lugar de aprendizaje y a la muerte del santo turinés funcionaban o comenzaban a funcionar varias escuelas profesionales en diferentes partes del mundo: Sampierdarena y San Benigno Canavese en Italia, Ios Ateliers professionels de l'Association du Patronage St.-Pierre en Niza (1875), los Talleres de Buenos Aires (1877) o los Talleres salesianos en Barcelona (1884). A estas casas y a las que vinieran en el futuro Don Bosco legó un modelo (el Oratorio de Valdocco), un diseño, unos principios organizativos, una dirección general, algunos hombres especialmente dedicados a ellas (coadjutores) y una espiritualidad del trabajo y de la dignidad humana.

\section{CAMIIIAROO JUกTOS}

Cada uno de nosotros tenemos que encontrar nuestro sitio en la vida, construir el proyecto de vida que nos haga plenamente felices y nos permita desarrollar nuestras cualidades al máximo. Tenemos capacidades diferentes y no hay nadie que no pueda desarrollarlas cuando encuentra algo que le motiva, que le anima a esforzarse por conseguir esa meta. Cada uno de nosotros somos únicos. Es por eso que tiene que haber jóvenes que estudien carreras universitarias y otros que completen su educación en la formación profesional preparándose para ser buenos profesionales.

Familia y escuela jugamos un papel clave en la orientación profesional y vocacional de los niños y jóvenes que son el futuro de nuestra sociedad. Ayudarles a tomar una buena decisión en sus estudios marcará su porvenir. No tengamos miedo a orientarles, si es que así lo juzgamos adecuado, a la formación profesional. Es una vía tan necesaria para la sociedad como la de aquellos que realizan una carrera universitaria. Necesitamos personas competentes en su trabajo, sea el que sea.

¿Cómo llevo a cabo la orientación vocacional y profesional de mis hijos/alumnos? ¿Te cuesta orientar a tus hijos/alumnos a realizar un ciclo de formación profesional? ¿Por qué? ¿Qué visión tienes de la formación profesional?

\section{Las experiencias vividas por Don Bosco marcarán su pasión por los jóvenes y sus proyectos, para dar una casa estable a estos chicos, una buena instrucción y ayudarles a descubrir su camino en la vida}

\section{La centenaria escuela profesional salesiana}

En 1895 Don Rua, primer sucesor de Don Bosco, escribía en una carta circular dirigida a los salesianos que, para evitar problemas y para darles el verdadero nombre a nuestros talleres, se les debe llamar "Escuelas Profesionales". Esta formación profesional incipiente con el paso del tiempo se ha ido adaptando a las circunstancias de cada momento histórico. Desde aquellos inicios humildes hasta nuestros días han sido muchas las casas salesianas que se han abierto por todo el mundo y, entre ellas, muchas las que cuentan con escuelas de formación profesional, poniendo de manifiesto nuestra particularidad y nuestros orígenes carismáticos, en los que el salesiano coadjutor ha ocupado un lugar de primer orden. 


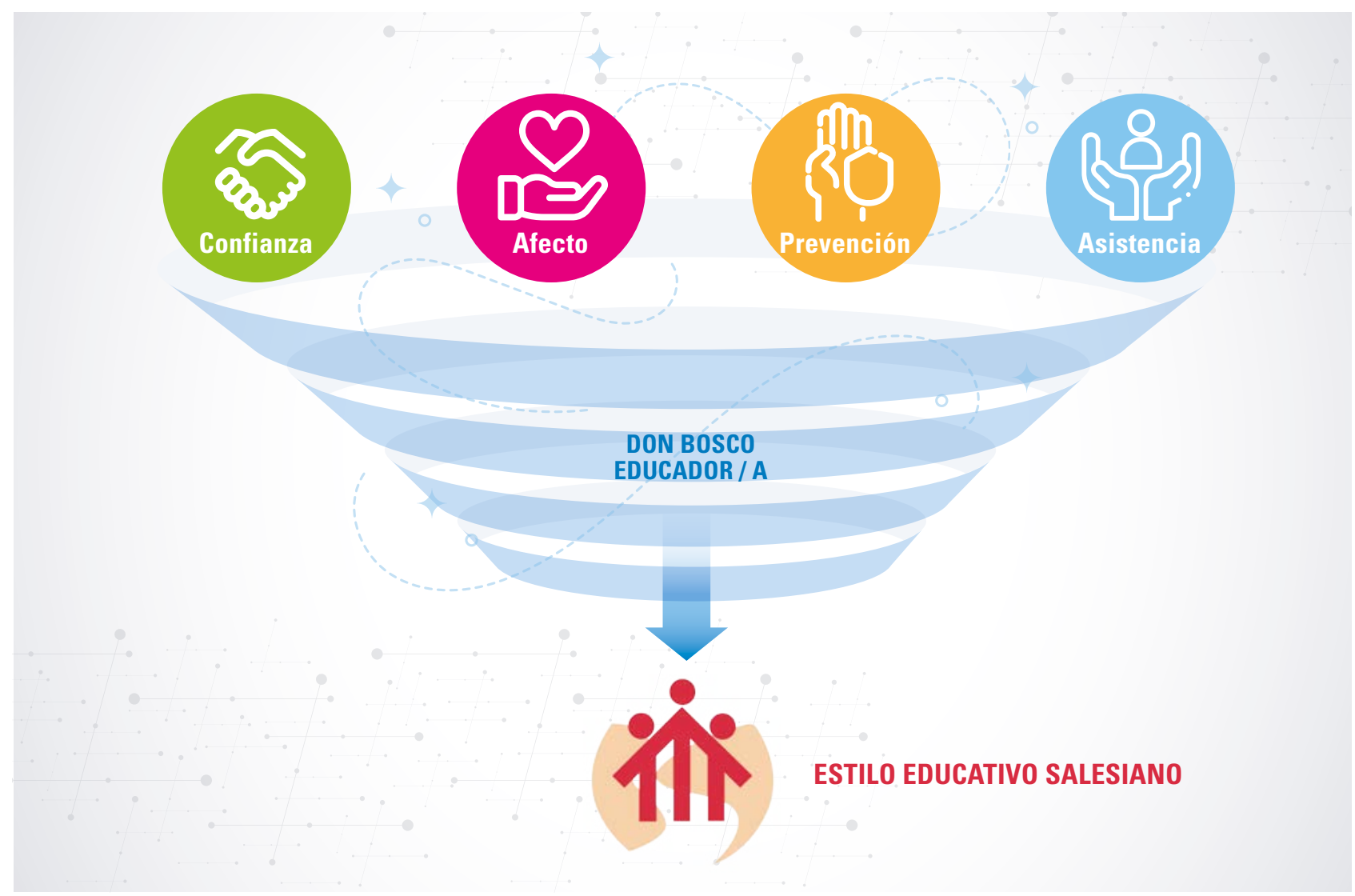

Los tiempos han cambiado, las máquinas se han modernizado, las instalaciones han mejorado, pero el estilo educativo, independientemente del país en el que nos encontremos, sigue siendo el mismo:

ע Una formación que promueve el desarrollo humano, profesional y religioso de los jóvenes.

ע Una educación que busca preparar a los jóvenes para tener un futuro mejor y una inserción laboral en un mundo marcado, especialmente en nuestro país, por una situación preocupante de paro juvenil.

ע Una apuesta por la prevención, la integración y la participación.

ע Una acogida, familiaridad, confianza y cercanía que definen nuestro modo de tratar a los jóvenes.

\section{HEMOS HABLADO DE}

\section{Educación; prevención; formación profesional; taller de formación; asistencia.}

Este artículo fue solicitado por PADRES Y MAESTROS en septiembre de 2020, revisado y aceptado en febrero de 2021.
ע Una relación educativa que intenta sacar lo mejor de cada persona, ver lo positivo y potenciar las posibilidades de cada uno.

ע Un trato respetuoso que ha puesto siempre al joven en el centro del proceso educativo convirtiéndolo en protagonista de su propio aprendizaje.

ע Una mirada amable y una preocupación constante que se extiende más allá de las aulas y perdura en el tiempo; dan muestra de ello tantos antiguos alumnos que han pasado por nuestros colegios salesianos.

Hoy como ayer, la escuela profesional salesiana trata de "formar buenos cristianos y honrados ciudadanos" •

\section{DARA SABER MÂS}

Lenti, A. (2011). Don Bosco: historia y carisma 2. Expansión: de Valdocco a Roma (1850-1875). Madrid: CCS.

Petitclerc, J. M. (dir.). (2020). Formación profesional salesiana. Una oportunidad con el estilo de Don Bosco. Madrid: CCS.

Prellezo, J. M. (2012). Las escuelas profesionales salesianas. Momentos de su historia. Madrid: CCS. 